\title{
Introducing Surface-Enhanced-Raman-Scattering Enhancer for Experimental Estimation of Debye Screening Length in Organic Field Effect Transistors
}

Hao Li\#, Cong Wang\#, Meihua Shou, Yanrui Lin, Xuehua Hou, Zengqi Xie, Linlin Liu ${ }^{\text {a) }}$

Institute of Polymer Optoelectronic Materials and Devices, Key Laboratory of Luminescence from Molecular Aggregates of Guangdong Province, State Key Laboratory of Luminescent Materials and Devices, South China University of Technology, Guangzhou 510640, P. R. China

a) Author to whom correspondence should be addressed msliull@scut.edu.cn

\# These authors contributed equally to this work. 
(a)

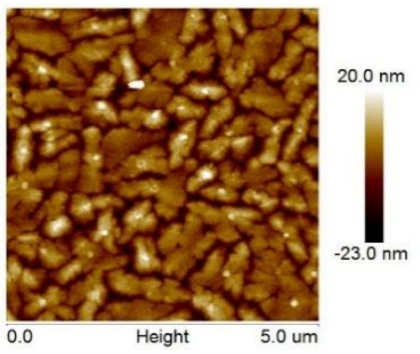

(b)

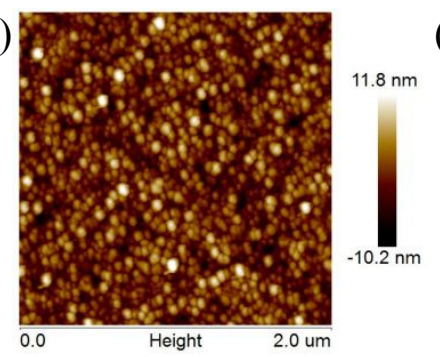

(c)

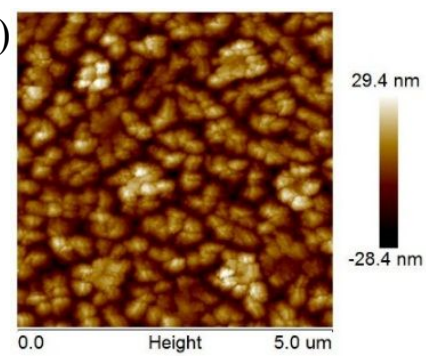

Figure S1. Atomic force microscope (AFM) characterizations of (a) the first $15 \mathrm{~nm}$ thick pentacene layer deposited on the PMMA substrate; (b) the 5nm silver nanoparticles evaporated on the first pentacene layer; (c) the second $25 \mathrm{~nm}$ thick pentacene layer deposited on silver nanoparticles.

(a)

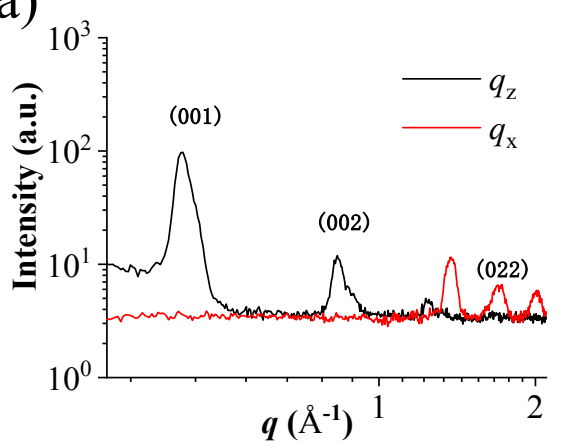

(b)

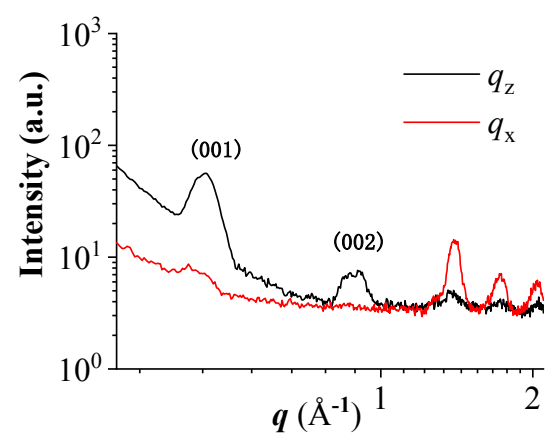

Figure S2. Line cuts of the GIWAXS images of pentacene evaporated on $\mathrm{SiO} 2$ (a) and silver nanoparticles substrates (b) respectively. 

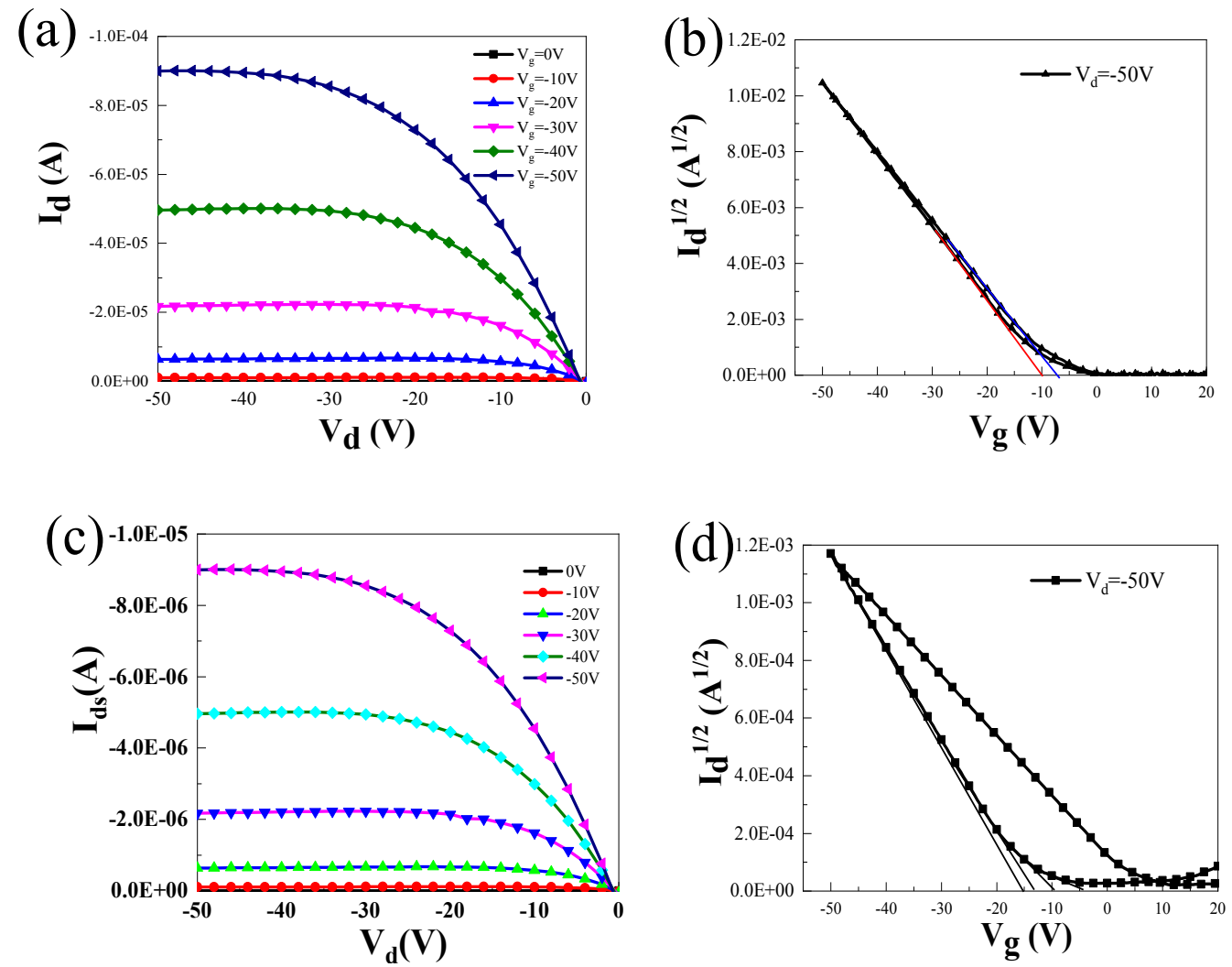

Figure S3. Output and transfer characteristic curves of control device $(a, b)$ and the Ag-15 device (c,d) respectively.

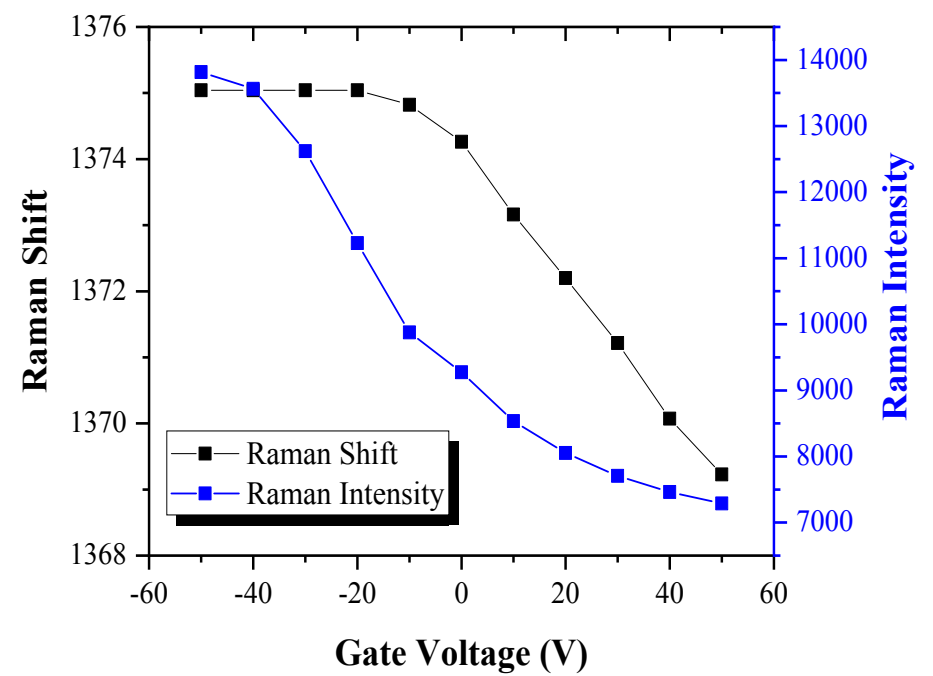

Figure S4. Variation of Raman intensity and Raman shift of characteristic peak with gate voltage 

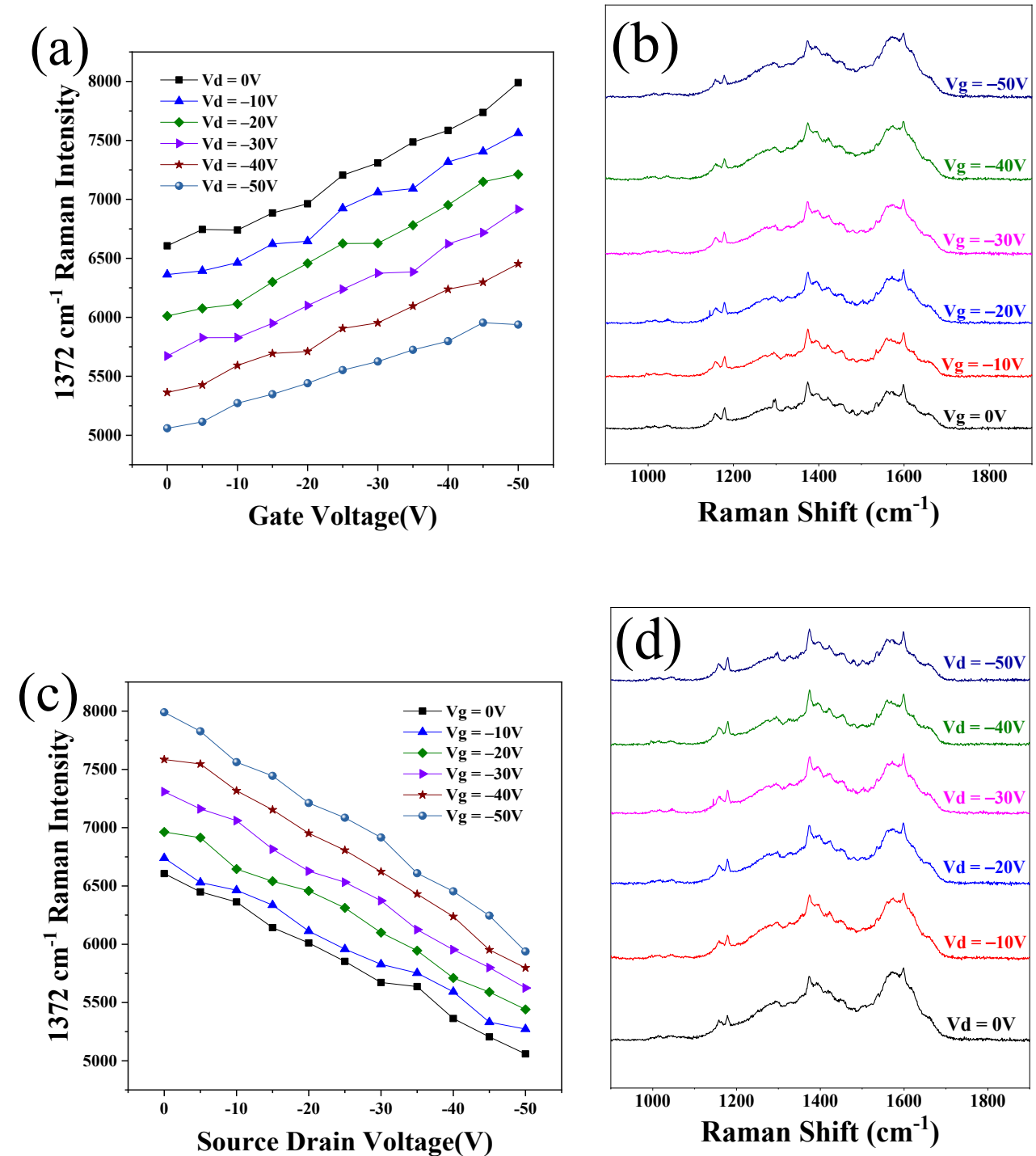

Figure S5. Profiles of the Ag-15 device Raman shift intensity and the Raman spectra as a function of applied source-drain $(a, c)$ voltage and gate voltage $(b, d)$ respectively. 
(a)

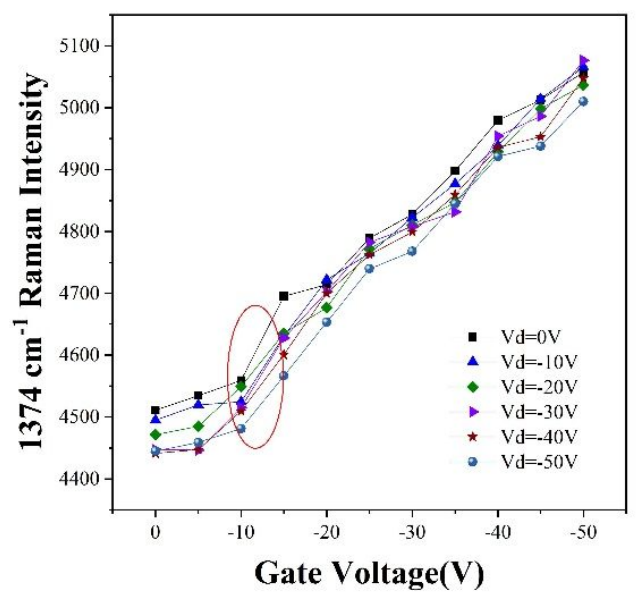

(b)

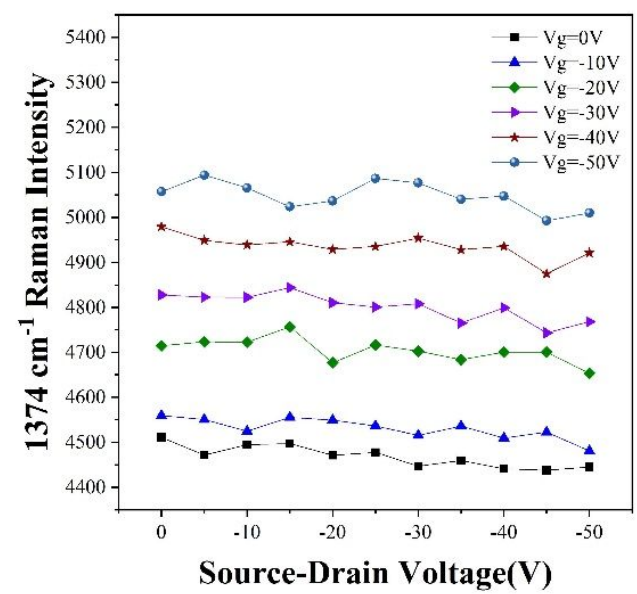

Figure S6. Profiles of the control device Raman intensity as a function of applied gate voltage and source-drain voltage.The laser power of Raman measurement is 100 times stronger than that use in SERS measurement.

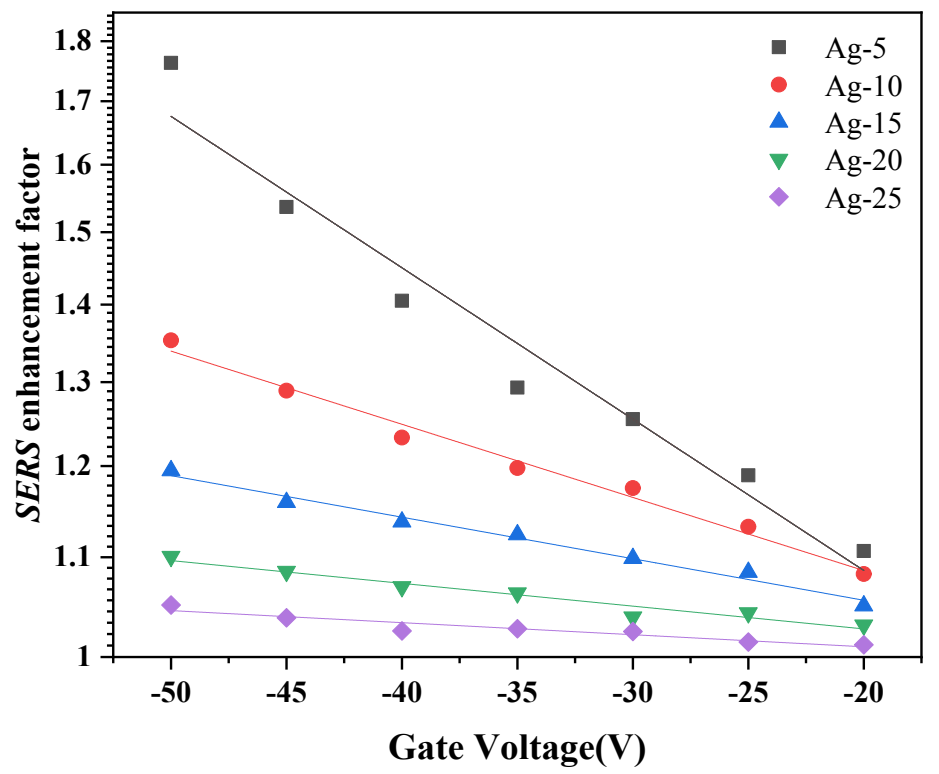

Figure S7. Normalized $S E R S$ enhancement factor $\left(\mathrm{I} / \mathrm{I}_{0}\right)$ as a function of gate voltage. 


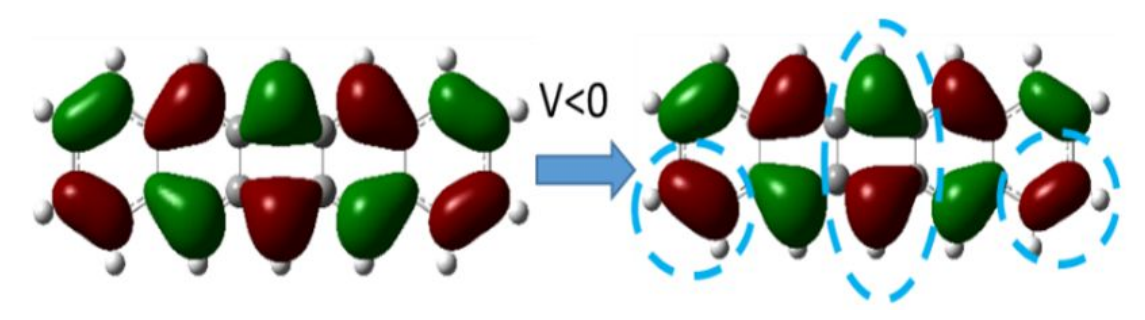

Figure S8. The change of electron cloud distribution (HOMO) of pentancene under an electric field (2.5 $\mathrm{e}^{-3}$ a.u.) along the long axis direction of pentancene ( $\mathrm{z}$ direction).

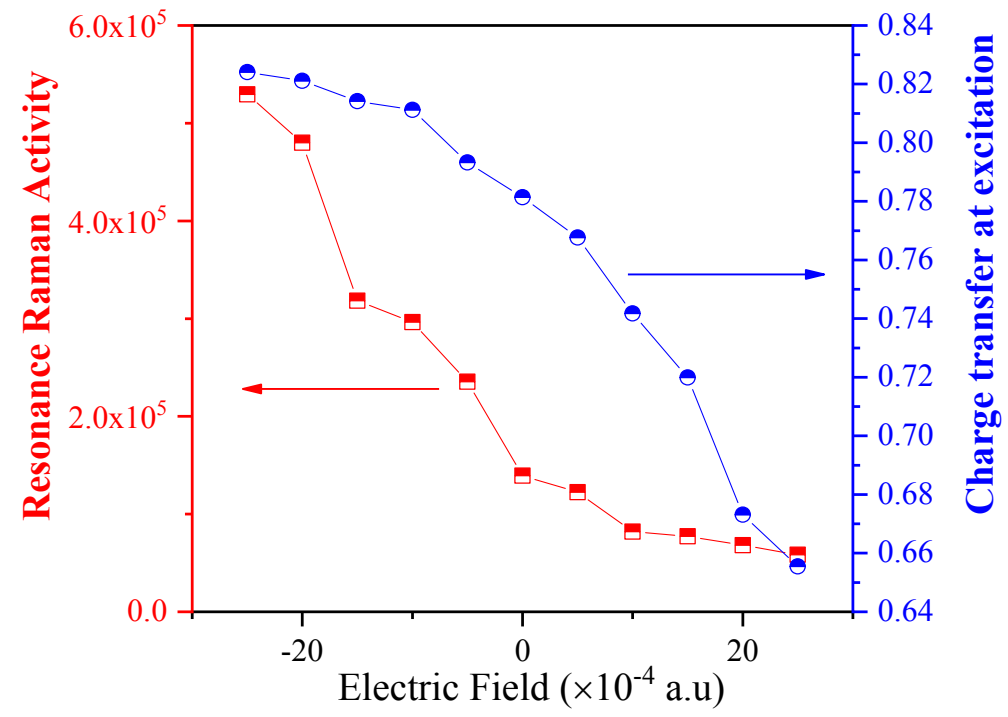

Figure S9. Variation of resonance Raman activity and charge transfer number with electric field. 
Table S1. Main performance parameters of the pure pentacene OFET and the Ag-15 device ( $z$ is the depth of Ag NPs in pentacene)

\begin{tabular}{ccccc}
\hline Parameters & $\begin{array}{c}\text { Mobility } \\
{\left[\mathbf{c m}^{2} /(\mathbf{V} \cdot \mathbf{s})\right]}\end{array}$ & $\begin{array}{c}\text { Forward } \\
\text { Threshold Voltage } \\
{[\mathbf{V}]}\end{array}$ & $\begin{array}{c}\text { Back Threshold } \\
\text { Voltage }[\mathbf{V}]\end{array}$ & $\begin{array}{c}\text { On/Off Ratio } \\
{\left[\times \mathbf{1 0}^{5}\right]}\end{array}$ \\
\hline Control device & $0.12 \pm 0.037$ & $-8 \pm 3.1$ & $-11 \pm 2.6$ & $2.13 \pm 0.17$ \\
\hline Silver nanoparticles & $0.021 \pm 0.007$ & $-14 \pm 2.3$ & $6 \pm 1.4$ & $0.34 \pm 0.11$ \\
\hline
\end{tabular}

Table S2. $\mathrm{V}_{\text {(th,back) }}$ of devices with different nanoparticle depth

\begin{tabular}{|c|c|}
\hline Geometry & $\boldsymbol{V}_{\text {(th,back) }}[\mathbf{V}]$ \\
\hline $\mathrm{Ag}-5$ & 7 \\
\hline $\mathrm{Ag}-10$ & 7 \\
\hline $\mathrm{Ag}-15$ & 6 \\
\hline $\mathrm{Ag}-20$ & 3 \\
\hline $\mathrm{Ag}-25$ & -2 \\
\hline
\end{tabular}


Table S3. Excited states and corresponding excitation properties of Pentacene- $\mathrm{Ag}_{18}$ with larger oscillator strength and excitation wavelength less than or close to $532 \mathrm{~nm}$.

\begin{tabular}{|c|c|c|c|c|}
\hline $\begin{array}{c}\text { excited } \\
\text { state }\end{array}$ & $\begin{array}{c}\text { excitation } \\
\text { energy }(e V)\end{array}$ & $\begin{array}{c}\text { excitation } \\
\text { wavelength }(\mathbf{n m})\end{array}$ & $\begin{array}{l}\text { oscillator } \\
\text { strength }\end{array}$ & $\begin{array}{c}\text { charge density } \\
\text { difference }\end{array}$ \\
\hline 6th & 1.17 & 1055 & $f=0.1250$ & \\
\hline 11th & 1.34 & 924 & $f=0.1465$ & \\
\hline 24th & 2.06 & 602 & $f=0.2414$ & \\
\hline 27 th & 2.17 & 570 & $f=0.3630$ & \\
\hline 35th & 2.38 & 520 & $f=0.1587$ & \\
\hline 37th & 2.44 & 508 & $f=0.7593$ & \\
\hline
\end{tabular}

